Research Article

\title{
Research on Utility Evaluation of Grid Investment considering Risk Preference of Decision-Makers
}

\author{
Hongliang Wu, Daoxin Peng $(\mathbb{D}$, and Ling Wang \\ Energy Development Research Institute, CSG, 510623, Guangzhou, China \\ Correspondence should be addressed to Daoxin Peng; pengdaoxin92@163.com
}

Received 20 March 2020; Revised 16 June 2020; Accepted 22 June 2020; Published 29 July 2020

Guest Editor: Shianghau Wu

Copyright ( $\odot 2020$ Hongliang Wu et al. This is an open access article distributed under the Creative Commons Attribution License, which permits unrestricted use, distribution, and reproduction in any medium, provided the original work is properly cited.

\begin{abstract}
Effectiveness evaluations are one of the important ways to guide grid investment and to improve investment efficiency. Improving the effectiveness of grid investment evaluations is studied based on the optimization of the investment evaluation index system and the utility evaluation model. The index system is optimized by establishing an evaluation index system of grid investment effectiveness, considering the redundancy between the indices, and constructing an ISM-DEA model. The utility function model was introduced to fully consider the different risk appetites of decision-makers, and a utility evaluation model that takes risk appetite into account was established. An improved weight integration model based on multiobjective optimization was established by considering the minimum deviation and the trend-optimal objective function when setting the index weights. The calculation results show that the feasibility of the index system optimization model and utility evaluation model constructed in this study is verified under the premise of satisfying the assumptions. By adjusting the risk preference coefficient of decision-makers, the dynamic optimization of the grid investment utility evaluation results can be realized.
\end{abstract}

\section{Introduction}

The Central Committee of the Communist Party of China and the State Council formally issued "Several Opinions on Further Deepening the Reform of the Electric Power System" on March 15, 2015. With the continuous deepening of this round of the power system reform, the role of power grid companies in the power industry chain is required to gradually change to that of middlemen, who collect electricity transaction fees in the market environment. Subsequent documents, such as the supervision and review of transmission and distribution pricing costs, have caused grid companies to face greater investment risks-especially for researching and determining the effectiveness of grid investment - and have established higher investment evaluation work requirements for grid companies $[1,2]$.

The traditional assessment of power grid investment primarily focuses on technical indicators, and insufficient attention is given to economic and environmental benefit indicators. The many studies that address power grid investment assessment have limitations, and research on grid investment evaluation can be divided into the construction of evaluation index systems and the construction of evaluation models.

1.1. Evaluation Indicator System. Some scholars focus on the evaluation of a single indicator to establish an indicator system. For example, Psarros and Georgios $\mathrm{N}$ use the levelized cost of energy as the only primary evaluation index; a comprehensive evaluation index is developed to evaluate the potential of the energy system, which integrates all the technical, economic, and environmental performance indicators [3, 4]. A single indicator focuses on one aspect of the problem, and results are one-sided. More scholars now conduct research on the indicator system. For example, Yu $[5,6]$ constructed a multi-dimensional evaluation index system when studying the investment benefits of power grids and distribution network investments and applied them to power grid assessments. Jiang [7] used a neural network model to construct a grid investment evaluation index system that considered value at risk. Han [8] considered the 
effectiveness of micro-grid investment for photovoltaic and energy storage access and constructed a multi-dimensional evaluation index system for the effectiveness of micro-grid investment.

1.2. Evaluation Model. Scholars have completed abundant research in fields related to evaluation models. For example, Guo [9] used the correlation feature fusion analysis, correlation tests, and statistical analysis for the fuzzy attribute feature decomposition of power grid investment benefit evaluation. A regression analysis of the samples helps achieve accurate prediction and quantitative evaluation of power grid investment benefit evaluation. Xiaobao Yu $[10,11]$ performed evaluation research on the value of power customers by constructing an index weighting model under multi-objective function optimization. Xing [12] used the set pair analysis method to construct a grid investment evaluation model and a single factor sensitivity analysis method and model to calculate the grid project investment benefit. $\mathrm{He}$ [13] established a sound evaluation index system for power grid investment projects and adopted a DEA analysis model to perform evaluation research. Sun [14] realized evaluation research on grid investment by constructing an evaluation model based on an improved DEA and Monte Carlo simulation; Yu $[15,16]$ used the value-at-risk theory introduced into a comprehensive energy system assessment and constructed an assessment based on the CVaR theory and multiobjective optimization index weighting models.

In addition to the evaluation index system and the evaluation model, research on power grid investment evaluation also involves risk assessment issues. Negnevitsky [17] presented a risk assessment approach to analyze power grid system security for operation planning with high wind power generation penetration. Liang [18] proposed a novel risk-based uncertainty set optimization method for the energy management of typical hybrid AC/DC microgrids, where RPG outputs are considered to be the major uncertainties. Karki [19] presented a generalized and approximate risk-based method that is relatively simple to apply. Cao [20] presented a methodology based on cyber-power joint analysis to quantitatively evaluate the operational risk of ADNs caused by cyber contingencies.

Analysis of previous research reveals many studies on power grid investment evaluation, but deficiencies exist. First, in the construction of a power grid investment evaluation index system, more consideration is given to technical indexes than to social and environmental benefits, and the coupling between indexes is not addressed. Second, conventional single evaluation methods are typically selected; some scholars use a variety of evaluation theories, producing a lack of research results that consider the risk preference of evaluation subjects. Therefore, this study optimizes two aspects of the research on power grid investment effectiveness evaluation. A comprehensive dimension and oriented and optimized index system is important for the construction of a multidimensional evaluation index system. The utility function theory is used during the construction of the evaluation model to embed the risk preference of the decision-maker. The specific novelties of this study are the following:

(1) Optimization of the evaluation index system of conventional power grid investment effectiveness, construction of an improved ISM-DEA model, division of index types by using the relationship between indexes, and measurement of the influence of each index on the evaluation results by using the control variable method to eliminate the indexes with the least influence, solving the problem of index coupling and optimizing the index system.

(2) Combination of two mutually informative methods considering a variety of evaluation weight results, consideration of the advantages and disadvantages-any subjective or objective weighting method has disadvantages when used alone-of different methods, maximization of the characteristics of various weight results, and a proposal for the construction of a comprehensive weight calculation model based on the moment estimation theory.

(3) Construction of the utility evaluation power grid investment model based on risk preference, configuration of risk preference parameters by embedding the degree of risk preference of decision-makers in the utility function to influence the evaluation model results by adjusting the risk preference coefficient to realize the dynamic evaluation adjustment results according to different people.

This article is divided into five parts. The first is an introduction that outlines the research background and current development status of power grid investment assessment. The second and third parts are the main bodies of this dissertation. The second part primarily screens power grid investment effectiveness indicators and establishes a conventional grid investment index system and an index optimization model. The third part introduces the utility function theory, designs the risk preference coefficient of the decision-maker, and inserts said coefficient into the utility function theory to construct the utility evaluation model of power grid investment based on risk preference. The fourth part performs the simulation analysis of the model and the routine and comparison analyses of the simulation result. The fifth part is the conclusion and summarizes the results and future research prospects.

\section{Construction and Optimization of the Investment Effectiveness Evaluation Index System}

2.1. Establishment of the Evaluation Indicator System. The evaluation of the effectiveness of power grid investment primarily considers the multiple economic, environmental, social, and technical benefits. Literature searches and investigation reveal many indicators that evaluate the effectiveness of power grid investment and highlight its importance in the construction of an indicator system. The 
Table 1: Power grid investment effectiveness evaluation index system.

\begin{tabular}{|c|c|c|c|}
\hline First-level indicator & Second-level indicator & Third-level indicators & Index number \\
\hline \multirow{16}{*}{ Grid investment effectiveness evaluation } & \multirow{6}{*}{ Economic benefits } & New investment included in fixed assets ratio & $\mathrm{A}_{1}$ \\
\hline & & Unit new asset pricing cost & $\mathrm{A}_{2}$ \\
\hline & & Asset utilization efficiency & $\mathrm{A}_{3}$ \\
\hline & & Weighted average return on capital & $\mathrm{A}_{4}$ \\
\hline & & Unit asset pricing depreciation fee & $\mathrm{A}_{5}$ \\
\hline & & Life-cycle return on investment & $\mathrm{A}_{6}$ \\
\hline & \multirow{3}{*}{ Social benefits } & Investment power growth ratio & $\mathrm{B}_{1}$ \\
\hline & & User reliability & $\mathrm{B}_{2}$ \\
\hline & & System reliability & $\mathrm{B}_{3}$ \\
\hline & \multirow{3}{*}{ Environmental benefits } & $\mathrm{CO}_{2}$ emission reduction rate & $\mathrm{C}_{1}$ \\
\hline & & Proportion of clean energy power generation capacity & $\mathrm{C}_{2}$ \\
\hline & & Pollutant emission reduction rate & $\mathrm{C}_{3}$ \\
\hline & \multirow{4}{*}{ Technical benefits } & Qualified rate of voltage & $\mathrm{D}_{1}$ \\
\hline & & Node voltage ratio & $\mathrm{D}_{2}$ \\
\hline & & Average transfer ratio of transmission line & $\mathrm{D}_{3}$ \\
\hline & & Network coordination & $\mathrm{D}_{4}$ \\
\hline
\end{tabular}

following basic principles of indicator system construction must be met:

(1) Systematic: there must be a certain logical relationship between the indicators, which must reflect the principal characteristics and status of the distribution network from different aspects and the characteristics of the internal relationship of safetyreliability-economics. The construction of the indicator system must have a hierarchical structure, from top to bottom and from the macro- to micro-level layers to form an organic unity.

(2) Scientific: the design and selection of each index must have a scientific basis, which can objectively, representatively, and truly reflect the engineering characteristics and social economic benefits of the distribution network. The design should not be excessively small or simple to avoid the omission of object information and inaccurate evaluation results.

(3) Comparability: the calculation measures and calculation methods for index selection must be consistent and unified. Each index is simple and clear and has a strong microcosm.

(4) Measurability: the selection should consider the convenience of the indicator data for collection and measurement; the ability to be quantitatively processed is important to facilitate mathematical calculation and analysis.

(5) Independence: the physical and social attributes of the objects reflected by the indicators should be independent of each other and should not overlap.

On this basis, a set of index systems applicable to the evaluation of grid investment effectiveness is constructed and divided into three levels. The first level is the target level, which is the grid investment effectiveness evaluation. The second level is the criterion level, including the four major technical, economic, social, and environmental index attributes. The thirdlevel (index layer) contains 16 indicators (Table 1).
2.2. Index Optimization Model. Effective research is necessary for the grid investment evaluation index system focused on the construction of an effectiveness evaluation model. Before constructing the model, the index system is optimized and screened to improve scientificity and rationality. Therefore, the effectiveness evaluation model of power grid investment is divided into two parts. The first part and second part are the model index optimization and the effectiveness evaluation, respectively. Index optimization modeling primarily uses the improved ISM-DEA model and the control variable method to optimize the index. The effectiveness analysis of the optimized index system was performed based on the utility function to measure the investment effectiveness results of each evaluation object.

2.2.1. Standardization of Indicators. Considering the complexity of the grid investment effectiveness evaluation indicator data, there are many different types of indicators; the original data of the indicators must be processed first and can generally be classified into three categories.

(1) Positive Index. Positive indicators are converted into standard values by setting indicator thresholds, including upper $\left(x^{\max }\right)$ and lower $\left(x^{\min }\right)$ limits.

The standardization formula of the indicator is as follows:

$$
y=\frac{x-x^{\min }}{x^{\max }-x^{\min }} \times 0.3+0.7
$$

(2) Reverse Indicator. The reverse indicator sets the indicator threshold, including the upper $\left(x^{\max }\right)$ and lower $\left(x^{\min }\right)$ limits. The lower limit of the forward indicator generally refers to the optimal value, and that of the reverse indicator is converted into the standard value.

The standardization formula of the indicator is as follows: 


$$
y=\frac{x^{\max }-x}{x^{\max }-x^{\min }} \times 0.3+0.7
$$

(3) Moderate Index. The normalization of the moderate index is based on the inverse index processing function; the first step is to set an optimal moderate value $x^{\text {mid }}$ and to convert the moderate index into the reverse index according to the following formula:

$$
x^{\prime}=\left|x-x^{\mathrm{mid}}\right| \text {. }
$$

The index is then processed as an inverse indicator and converted to a standard value.

2.2.2. ISM Model. The interpreted structure model method is a specialized research method used to analyze the related structure of complex elements in educational technology research. The function uses the known random relationship between system elements to reveal the internal structure of the system. This study improves the structure interpretation model. The basic idea is based on the relational link diagram generated by the reachability matrix, selecting output and input indicators from the top and bottom, respectively. The workflow for explaining the structural model can be divided into the decision-making and calculation processing phases [14].

Step 1: enter the original data to form an $n \times m$ rank data matrix $A_{0}$ :

$$
A_{0}=\left[\begin{array}{ccccc}
x_{11} & x_{21} & x_{31} & \ldots & x_{n 1} \\
x_{12} & x_{22} & x_{32} & \ldots & x_{n 2} \\
\ldots & \ldots & \ldots & \ldots & \ldots \\
x_{1 m} & x_{2 m} & \ldots & \ldots & x_{n m}
\end{array}\right]
$$

Step 2: process $A_{0}$ and calculate the correlation coefficient between $n$ indicators. We take the $x_{1}$ and $x_{2}$ indicators as examples and calculate the correlation coefficient formula as follows:

$$
r_{12}=\frac{\sum x_{1 j} x_{2 j}-\left(\sum x_{1 j} \sum x_{2 j} / m\right)}{\sqrt{\left(\sum x_{2}^{1 j}-\left(\sum x_{1 j} / m\right)^{2}\right)\left(\sum x_{2}^{2 j}-\left(\sum x_{2 j} / m\right)^{2}\right)}} .
$$

Obtain $n \times n$ coefficient matrix $A_{1}$.

$$
A_{1}=\left[\begin{array}{cccc}
r_{11} & r_{12} & \ldots & r_{1 n} \\
r_{21} & r_{22} & \ldots & r_{2 n} \\
\ldots & \ldots & \ldots & \ldots \\
r_{n 1} & \ldots & \ldots & r_{n n}
\end{array}\right]
$$

Step 3: process matrix $A_{1}$ in the following manner: if $r_{i j}>\alpha$, let $r_{i j}=1$; otherwise, let $r_{i j}=0$; the value of $\alpha$ can be defined (generally 0.85 ) to obtain the $n \times n$ order adjacency matrix $A_{2}$ :

$$
A_{2}=\left[\begin{array}{cccc}
1 & 1 & \ldots & 0 \\
1 & 1 & \ldots & 0 \\
\ldots & \ldots & \ldots & \ldots \\
0 & 0 & \ldots & 1
\end{array}\right] .
$$

Step 4: process matrix $A_{2}$; the $n \times n$ reachable matrix $A_{3}$ can be obtained by processing. $A_{2}$ and $A_{3}$ satisfy the following rules:

$$
\left(A_{2}+I\right)^{k-1} \neq\left(A_{2}+I\right)^{k}=\left(A_{2}+I\right)^{k+1}=A_{3} .
$$

Step 5: division and level division. First, the matrix $A_{3}$ is processed to find the reachable set $\mathrm{P}$, antecedent set $\mathrm{Q}$, and intersection $\mathrm{S}$ :

Solve P: find the column corresponding to element 1 in each row

Solve Q: find the row with element 1 in each column Solve S: apply the function that comes with MATLAB

The reachable set $\mathrm{P}$, antecedent set $\mathrm{Q}$, and intersection $\mathrm{S}$ are obtained through processing.

Step 6: perform processing based on the PQS set obtained in step 5, and perform level division. Through processing, several levels and indicators contained in each level class can be obtained. According to this classification, an indicator level map can be drawn.

Step 7: select the index from the highest level and select the previous index as the output-based index; select the index from the lowest level and select the previous index as the input-based index.

Step 8: output the result and driving indicator groups.

Figure 1 shows the specific process.

2.2.3. Improving the Data Envelope Analysis. Data envelopment analysis (DEA) is a method based on the concept of relative efficiency that evaluates the effectiveness of multiinput and multi-output decision units with the same type [12]. The basic idea is to treat an economic system or the production process (one unit) as an entity within a certain range of possibilities by assigning a number of production factors and output of a certain number of "product" activities as entities (units) called decision-making units (DMU); the group of numerous DMU is evaluated by analysis of the input or output ratios, with the weight of each DMU input or output indicator to evaluate for the variable operation and determine an efficient production frontier. The effectiveness of each DMU is determined according to the distance between each DMU and the effective production front. The projection method is used to signal the 


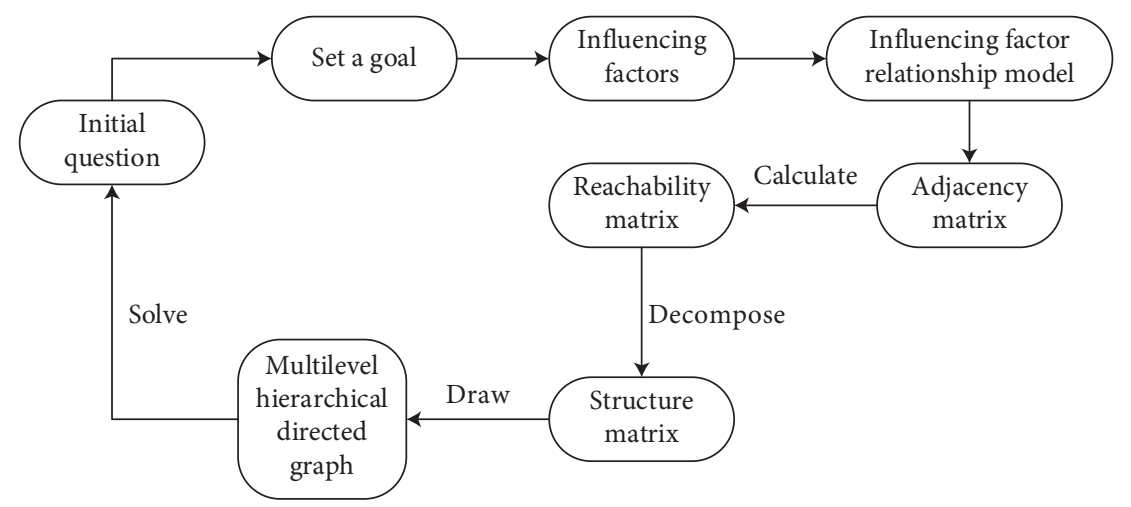

FIgURe 1: Structural model flow diagram.

reasons for non-DEA effective or weak DEA effective DMU and the direction and degree of improvement.

The data envelope evaluation model evaluates the investment efficiency of power grid companies and has been improved to consider the continuity of the development and construction of power grid companies; thus, the power grid construction effect at the end of the previous time period should translate to the next time period. The initial conditions for the start and the management efficiency evaluation model established in this study are dynamic and defined as the D-dynamic data envelope model (D-DEA). The benefits provided by the construction investment of one attribute can become the construction investment of another attribute. The objective function of the data envelope evaluation model constructed in this study is as follows:

$$
\min \frac{\sum_{t=1}^{T} W^{t}\left(\sum_{k=1}^{K} \omega^{k}\left(1-\left(1 / m_{k}\right) \sum_{i=1}^{m_{k}}\left(s_{\mathrm{iok}}^{t-} / x_{\mathrm{iok}}^{t}\right)\right)\right)}{\sum_{t=1}^{T} W^{t}\left(\sum_{k=1}^{K} \omega^{k}\left(1+\left(1 / r_{k}\right) \sum_{i=1}^{r_{k}}\left(s_{\text {rok }}^{t+} / y_{\text {rok }}^{t}\right)\right)\right)} .
$$

Here, $x_{i j k}^{t}$ represents the value of the input index $i$ under the attribute $k$ of the decision unit $j$ in $t$ years. $y_{r j k}^{t}$ represents the value of the output index $i$ under the attribute $k$ of the decision unit $j$ in $t$ years. $s_{i j k}^{t-}$ represents the relaxation variable of the input index $i$ under the attribute $k$ of the decision unit $j$ in $t$ years. $s_{r j k}^{t+}$ represents the relaxation variable of the output index $i$ under the attribute $k$ of the decision unit $j$ in $t$ years.

The constraints are as follows:

$$
\text { s.t. }\left\{\begin{array}{l}
\sum_{j=1}^{n} \lambda_{j k}^{t} x_{i j k}^{t}+s_{i k}^{t-}=x_{i o k}^{t}, o=1, \ldots, n ; k=1, \ldots, K ; i=1, \ldots, m ; t=1, \ldots, T, \\
\sum_{j=1}^{n} \lambda_{j k}^{t} y_{r j k}^{t}-s_{r k}^{t-}=y_{r o k}^{t}, o=1, \ldots, n ; k=1, \ldots, K ; r=1, \ldots, s ; t=1, \ldots, T, \\
\sum_{j=1}^{n} \lambda_{j k}^{t} z_{j k_{i}}^{t, t+1}=\sum_{j=1}^{n} \lambda_{j k}^{t+1} z_{j k_{i}}^{t, t+1}, \\
\sum_{j=1}^{n} \lambda_{j k}^{t} z_{j(k, h)_{i}}^{t}=\sum_{j=1}^{n} \lambda_{j h}^{t+1} z_{j(k, h)}^{t}, \\
\sum_{j=1}^{n} \lambda_{j}^{k}=1, k=1, \ldots, K, \\
\lambda_{j k}^{t} \geq 0, s_{i}^{k-} \geq 0, s_{r}^{k+} \geq 0, i=1, \ldots, m ; r=1, \ldots, s ; k=1, \ldots, K .
\end{array}\right.
$$

Here, $z_{j(k, h)_{i}}^{t}$ represents the correlation value of the decision unit $j$ from the $k$ attribute to the $h$ attribute in the $t$ period. $z_{j k_{j}}^{t, t+1}$ represents the influence value of the attribute $k$ of the decision-making unit $j$ from year $t$ to year $t+1$.

Through optimization and adjustment of the model, the setting parameters change as follows:

$$
\begin{aligned}
& \sum_{j=1}^{n} \lambda_{j k}^{t} z_{j(k, h)_{i}}^{t}=z_{o(k, h)_{i},}^{t} \\
& \sum_{j=1}^{n} \lambda_{j h}^{t} z_{j(k, h)_{i}}^{t}=z_{o(k, h)_{i} .}^{t}
\end{aligned}
$$

From this, the efficiency value of each decision unit for each year can be obtained as follows:

$$
\theta_{o}^{t}=\frac{\sum_{k=1}^{K} \omega^{k}\left(1-\left(1 / m_{k}\right) \sum_{i=1}^{m_{k}}\left(s_{i o k}^{t-} / x_{i o k}^{t}\right)\right)}{\sum_{k=1}^{K} \omega^{k}\left(1+\left(1 / r_{k}\right) \sum_{i=1}^{r_{k}}\left(s_{\text {rok }}^{t+} / y_{\text {rok }}^{t}\right)\right)} .
$$

The efficiency value of each attribute of the decision unit DMU is calculated as follows:

$$
\theta_{o k}=\frac{\sum_{t=1}^{T} W^{t}\left(1-\left(1 / m_{k}\right) \sum_{i=1}^{m_{k}}\left(s_{i o k}^{t-} / x_{i o k}^{t}\right)\right)}{\sum_{t=1}^{T} W^{t}\left(1+\left(1 / r_{k}\right) \sum_{i=1}^{r_{k}}\left(s_{r o k}^{t+} / y_{r o k}^{t}\right)\right)} .
$$

The numerous indicators imply extensive evaluation when constructing the grid investment effectiveness evaluation index system. In this study, an improved DEA model is used to optimize the index system, thereby improving the efficiency and feasibility of the subsequent evaluation. Based on the principle of the control variable method, DEA is used to calculate the efficiency value of each evaluation object under the premise that different indexes are missing separately. The indexes are screened according to the variation in the efficiency value of each evaluation object. The first $\mathrm{N}$ indexes with the greatest impact are reserved according to actual needs that serve as the basis for the follow-up utility evaluation.

Taking the index data of each evaluation object in the year $t$ as an example, $x_{i j}$ indicates the input index value of $i$ in region $j$, and $y_{i j}$ indicates the output index value of $i$ in region $j$. Under normal circumstances, the evaluation efficiency value of each evaluation object is $\theta_{j 0}$. Assuming that one of the input indicators $x_{l}$ is eliminated, and the other indicators are unchanged, the evaluation efficiency value of 
each evaluation object is $\theta_{j l}$, and the change in the efficiency value of each evaluation object can be obtained as follows:

$$
\begin{aligned}
\Delta \theta_{j l} & =\frac{\left|\theta_{j l}-\theta_{j 0}\right|}{\theta_{j 0}} \times 100 \%, \\
\delta_{x_{l}} & =\frac{1}{j} \sum_{j=1}^{M} \Delta \theta_{j l} .
\end{aligned}
$$

The average efficiency change value $\delta_{x_{l}}$ of the input indicator $x_{l}$ is sorted in ascending order, the first $n(n<N)$ input indicators are eliminated as needed, and the remaining indicators are used as key input indicators for subsequent evaluation.

Assuming that an output index $y_{k}$ is eliminated and other indicators remain unchanged, the evaluation efficiency value of each evaluation object is $\theta_{j k}$, and the overall deviation rate of the evaluation object efficiency value is calculated as follows:

$$
S_{y_{k}}=\sqrt{\sum_{j=1}^{M}\left(\theta_{j k}-\frac{1}{j} \sum_{j=1}^{M} \theta_{j k}\right)^{2} .}
$$

The overall deviation rate $S_{y_{k}}$ of the output indicator $y_{k}$ is sorted in ascending order, the first $n(n<N)$ output indicators are eliminated as needed, and the remaining indicators are used as key output indicators for subsequent evaluation.

\section{Utility Evaluation Model considering Risk Preference}

3.1. Utility Theory. Utility theory is an economic theory that describes the ability of an article to satisfy human desires or the subjective psychological evaluation of the utility of an article to explain the value and its formation process [21]. Preference analysis, a principal component of utility theory, can reflect the risk preference of decision-makers. In this study, utility theory is applied to the evaluation of grid project investment effectiveness, and the corresponding effect function is obtained according to the risk appetite (conservative, aggressive, or neutral) of the investor:

$$
\begin{aligned}
& U=\alpha+\beta \ln \left[\sigma+\frac{\varepsilon^{2}}{1-2 \varepsilon}\right], \quad \varepsilon<0.5, \\
& U=\sigma, \\
& \mathcal{E}=0.5, \\
& U=1-\left|\alpha+\beta \ln \left\{1-\sigma+\frac{1-\varepsilon^{2}}{2 \varepsilon-1}\right\}\right|, \quad \varepsilon>0.5 .
\end{aligned}
$$

Here, $\varepsilon$ is the conversion coefficient; $\sigma$ is the normalized value of each index; and $U$ is the utility value. The conversion coefficient is determined according to the risk appetite of the decision-maker. The $\alpha$ and $\beta$ coefficients are obtained by using linear regression to obtain special utility points and

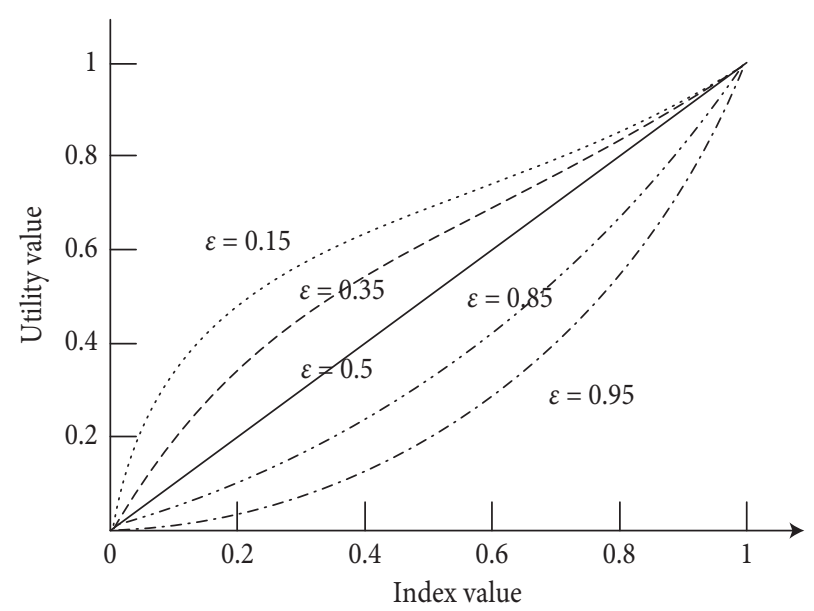

FIgURE 2: Utility function curve.

their corresponding $\sigma$ values. Figure 2 shows the utility function curve. The utility value and index value are standard values.

(1) When $\varepsilon<0.5$, the utility function curve is an upward convex curve, indicating that decision-makers are averse to risk, sensitive to loss responses, and conservative

(2) When $\varepsilon=0.5$, the utility function curve is a straight line, and decision-makers are risk-neutral

(3) When $\varepsilon>0.5$, the utility function curve is an upward concave curve. Decision-makers like risk, are sensitive to the benefit response, and are aggressive

When making decisions based on the utility function method, the risk attitudes of decision-makers under different $\varepsilon$ are different. Smaller and larger $\varepsilon$ values indicate more conservative and aggressive risk attitudes, respectively.

Because the goals of grid planning in different regions are different, the same grid investment criteria cannot be used to quantify the evaluation indicators. In the quantification process, both the characteristics of the indicators and the risk tolerance of the planning area must be considered. For example, in economically developed regions with high power grid quality requirements, excessive power outages are not allowed. From a risk perspective, reducing risks can be classified as risk aversion, and an evaluation plan for conservative decision-makers should be adopted. Less-developed areas can withstand the risk of power outages, pay more attention to economic development, and are classified as risky decision-makers. In this case, the evaluation scheme of aggressive decision-makers should be adopted.

3.2. Calculation of the Weight of Each Indicator. This study proposes an improved weight integration method based on multi-objective optimization to resolve the shortcomings of the single evaluation method and the disadvantages of combination weighting. This method takes into account the subjective consciousness of decision-makers and the objective characteristics of the data, minimizes deviations, and optimizes trends as the objective function of the integration 
weights. This study selects the reference object comparison judgment method and analytic hierarchy process as the subjective weighting method and selects the coefficient of variation method and the entropy weight method to perform objective observation of the index weights. The specific calculation model [22] and specific steps are as follows:

Step 1: define the objective function.

Setting the type of objective weighting method as $q$, the type of subjective weighting method as $p$, and the number of evaluation indicators as $n$, define the subjective weighting result as $W_{s}$ and the objective weighting result as $W_{t}$ :

$$
\begin{aligned}
& W_{s}=\left\{w_{s j}|1 \leq s \leq p, 1 \leq j \leq n|\right\}, \sum_{j=1}^{n} w_{s j}=1, w_{s j} \geq 0 \\
& W_{t}=\left\{w_{t j}|1 \leq t \leq q, 1 \leq j \leq n|\right\}, \sum_{j=1}^{n} w_{t j}=1, w_{t j} \geq 0 .
\end{aligned}
$$

Here, $w_{s j}$ indicates the weight of the index $j$ of the $s$-th subjective weighting method and $w_{t j}$ indicates the weight of the index $j$ of the $t$-th subjective weighting method.

The integration weight $W_{j}=\left[w_{1}, w_{2}, \ldots ., w_{n}\right]$ may first be assumed to minimize the deviation of the integration weight from the results of each weighting method; the objective function is

$$
\min H\left(w_{j}\right)=\zeta \sum_{s=1}^{p}\left(w_{j}-w_{s j}\right)^{2}+\psi \sum_{t=1}^{q}\left(w_{j}-w_{t j}\right)^{2}
$$

Here, $\zeta$ represents the degree of emphasis on subjective weighting results, and $\psi$ represents the degree of emphasis on objective weighting results.

Step 2: calculate the bias coefficient $\zeta, \psi$.

According to the basic idea of the moment estimation theory for each evaluation index, the expected values of the subjective weight and the expected value of the objective weight are

$$
\begin{aligned}
& E\left(w_{s j}\right)=\frac{\left(\sum_{s=1}^{p} w_{s j}\right)}{p}, 1 \leq j \leq n, \\
& E\left(w_{t j}\right)=\frac{\left(\sum_{t=1}^{q} w_{t j}\right)}{q}, 1 \leq j \leq n .
\end{aligned}
$$

Then, the weighting coefficient $\zeta_{j}, \psi_{j}$ of each indicator is

$$
\begin{aligned}
& \zeta_{j}=\frac{E\left(w_{s j}\right)}{E\left(w_{s j}\right)+E\left(w_{t j}\right)}, \\
& \psi_{j}=\frac{E\left(w_{t j}\right)}{E\left(w_{s j}\right)+E\left(w_{t j}\right)} .
\end{aligned}
$$

From this, the bias coefficient $\zeta, \psi$ can be calculated as

$$
\begin{aligned}
& \zeta=\sum_{j=1}^{n} \frac{\zeta_{j}}{n}, \\
& \psi=\sum_{j=1}^{n} \frac{\psi_{j}}{n} .
\end{aligned}
$$

Step 3: solve the minimum combined weight set.

Because of the difference in the index deviation and taking into account the calculation rationality, the degree of emphasis of all indicators is assumed to be the same, and the objective function is obtained as follows:

$$
\min H=\zeta \sum_{j=1}^{n} \sum_{s=1}^{p}\left(w_{j}-w_{s j}\right)^{2}+\psi \sum_{j=1}^{n} \sum_{t=1}^{q}\left(w_{j}-w_{t j}\right)^{2}
$$

The constraint function is

$$
\text { s.t. }\left\{\sum_{j=1}^{n} w_{j}=1,0 \leq w_{j} \leq 1,1 \leq j \leq n .\right.
$$

Step 4: solve the optimal combination weight set.

The fourth step is to optimize the comparison degree relationship between the indicators. Because the results (especially of subjective weighting) of different weighting theories on the importance of indicators differ, the following trend-optimal objective function is constructed to integrate the weight results and better reflect the importance degree relationship between indicators:

$$
\min G=\zeta \sum_{j=1, k=1, k \neq j}^{n} \sum_{s=1}^{p}\left(\frac{w_{j}}{w_{k}}-\frac{w_{s j}}{w_{k}}\right)^{2}+\psi \sum_{j=1, k=1, k \neq j}^{n} \sum_{t=1}^{q}\left(\frac{w_{j}}{w_{k}}-\frac{w_{t j}}{w_{k}}\right)^{2} .
$$

The constraint function is

$$
\text { s.t. }\left\{\sum_{j=1}^{n} w_{j}=1, \sum_{k=1}^{n} w_{k}=1,0 \leq w_{j} \leq 1,1 \leq j \leq n\right. \text {, }
$$

$0 \leq w_{k} \leq 1,1 \leq k \leq n$ 


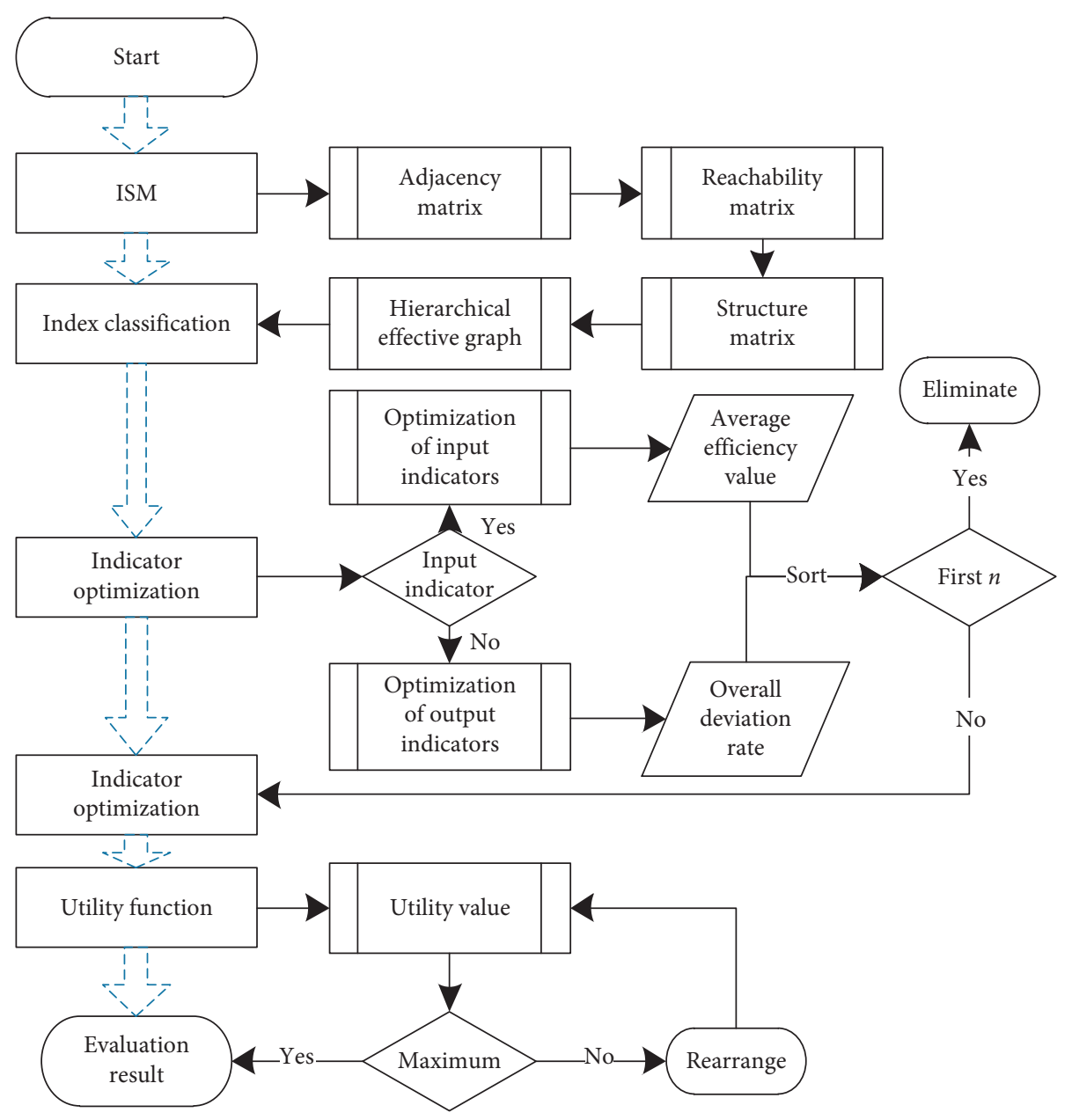

Figure 3: Algorithm flow.

Here, $w_{k}$ represents the integration weight of the indicator, and $w_{j}$ represents the weight of different indicators.

Step 5: solve the integrated weight set.

The last step is to combine the two objective functions, consider the minimum deviation and the optimal trend, and assume the same degree of importance to obtain the multiobjective function, as follows:

$$
\min Z=\frac{1}{2} \min H+\frac{1}{2} \min G .
$$

The weight combination under the multi-objective function is solved, and the weight result is defined as the final comprehensive evaluation weight.

3.3. Evaluation Model of Investment Effectiveness. The total utility value $U_{T}$ of the investment project $i$ is calculated based on the utility function. The existing method often uses a linear weighting method to obtain it, as shown in

$$
U_{T}(i)=\sum_{j=1}^{n} w_{i j} U_{i j} .
$$

The linear weighting method must be independent; however, the indicators in the system interact with each other. Using the linear weighting method creates evaluation result bias. Therefore, the total utility value of the target layer is obtained based on the distance vector merging rule, and the investment ranking of the construction projects is performed accordingly.

The utility value can be reduced to a real-valued function (consisting of the $\theta$ variable) to obtain the total utility from $\theta$. The function value of each point in the $\theta$-dimensional space constitutes a utility value surface. On a surface formed in b-dimensional space, there must be a single optimal point $\mathrm{E}$ $(1,1, \ldots, 1)$ and a single least ideal point $\mathrm{D}(0,0, \ldots, 0)$. The utility value corresponding to the ideal point is 1 . The utility value corresponding to the least ideal point is 0 . The other points are inferior to point $\mathrm{E}$ and superior to point $\mathrm{D}$ to varying degrees. The utility function value is between 0 and 1. Assume that the utility value surface is smooth and continuous. According to the distance vector merging rule, points on the plane closer to the optimal point have larger utility values, and vice versa. The distance from the point on the utility surface to the optimal point is 


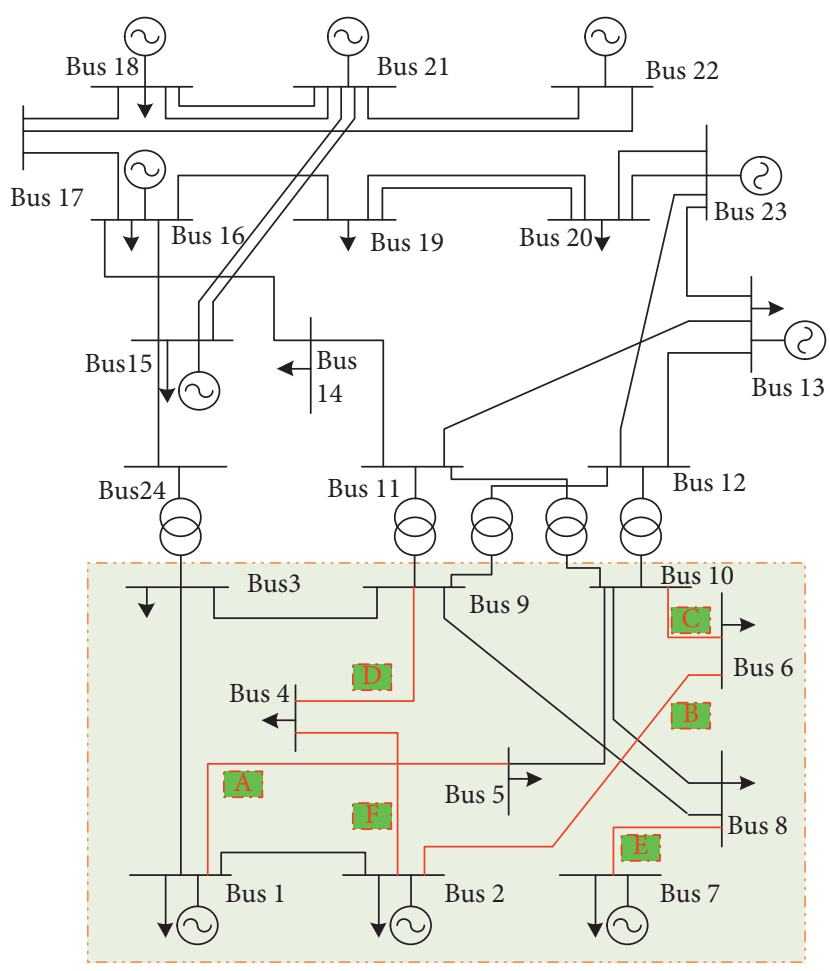

FIGURE 4: IEEE-RTS79 system diagram.

TABle 2: Project operation parameter setting.

\begin{tabular}{|c|c|c|c|c|c|c|}
\hline & Add point & Add load & Line length & New transformer capacity & Annual investment cost & Annual operating cost \\
\hline- & - & MW & $\mathrm{km}$ & $\mathrm{MV} \cdot \mathrm{A}$ & Ten thousand & Ten thousand \\
\hline Project A & Bus 1-bus 5 & 220 & 36 & 200 & 6520 & 520 \\
\hline Project B & Bus 2-bus 6 & 180 & 75 & 150 & 7215 & 560 \\
\hline Project C & Bus 6-bus 10 & 136 & 25 & 80 & 3443 & 500 \\
\hline Project D & Bus 4-bus 9 & 210 & 44 & 60 & 4040 & 590 \\
\hline Project E & Bus 7-bus 8 & 100 & 26 & 100 & 3820 & 500 \\
\hline Project F & Bus 4-bus 2 & 150 & 50 & 80 & 4120 & 550 \\
\hline
\end{tabular}

$$
d_{1}(i)=\sqrt{\sum_{j=1}^{n}\left[w_{i j}\left(1-U_{i j}\right)\right]^{2}} .
$$

The distance from point $\mathrm{E}$ to point $\mathrm{D}$ is $d_{2}(i)=\sqrt{\sum_{j=1}^{n} w_{i j}^{2}}$. Then, the total utility value $U_{T}$ of the project $i$ in the utility space can be expressed as

$$
U_{T}(i)=1-\frac{d_{1}(i)}{d_{2}(i)} .
$$

3.4. Algorithm Flow Design. By integrating the above algorithm models, the final power grid investment effectiveness evaluation model is obtained. Figure 3 shows the specific algorithm flow.

\section{Example Analysis}

4.1. Basic Assumptions. Regional power grid IEEE-RTS79 system (Figure 4) data was collected, and a number of project simulation runs were performed to sort out the simulation operation results data and to verify the feasibility of the power grid investment effectiveness evaluation index and evaluation model constructed in this study. The investment effectiveness of the project is evaluated according to the proposed evaluation model.

Suppose the transformer and transmission line are overloaded because of regional load growth, and the existing system needs to be planned. The marketization rate was 0.32 . Considering the complex terrain in this area, the cost of the transmission line project is 1.6 million yuan $/ \mathrm{km}$, the cost of the transformer project is $400,000 \mathrm{yuan} /(\mathrm{MV} \cdot \mathrm{A})$, the operating life is $16 \mathrm{y}$, and the construction period of new projects is $2 \mathrm{y}$. Table 2 shows the basic data of the 6 projects.

The index value was calculated according to the index type. The qualitative index reference [20] uses the trapezoidal fuzzy number method for quantification. The part of the quantitative index that involves future risk estimation and profit estimation is analyzed by a Monte Carlo simulation. Finally, we perform dimensionless processing (Table 3). 
TABLE 3: Dimensionless results of indicator data.

\begin{tabular}{|c|c|c|c|c|c|c|}
\hline & Project A & Project B & Project C & Project D & Project E & Project $\mathrm{F}$ \\
\hline$A_{1}$ & 0.500 & 0.000 & 1.000 & 0.773 & 0.636 & 0.409 \\
\hline $\mathrm{A}_{2}$ & 0.333 & 0.667 & 1.000 & 0.333 & 0.667 & 0.000 \\
\hline $\mathrm{A}_{3}$ & 0.700 & 0.000 & 0.800 & 0.400 & 1.000 & 0.400 \\
\hline $\mathrm{A}_{4}$ & 0.000 & 0.889 & 0.444 & 0.667 & 1.000 & 0.444 \\
\hline $\mathrm{A}_{5}$ & 0.600 & 1.000 & 0.400 & 0.200 & 0.000 & 0.800 \\
\hline $\mathrm{A}_{6}$ & 1.000 & 0.676 & 0.265 & 0.000 & 0.794 & 0.588 \\
\hline $\mathrm{B}_{1}$ & 1.000 & 0.143 & 0.000 & 0.571 & 0.429 & 0.071 \\
\hline $\mathrm{B}_{2}$ & 0.000 & 0.750 & 1.000 & 0.875 & 0.500 & 0.125 \\
\hline $\mathrm{B}_{3}$ & 1.000 & 0.500 & 0.000 & 0.500 & 0.000 & 1.000 \\
\hline $\mathrm{C}_{1}$ & 0.000 & 0.222 & 0.667 & 1.000 & 0.444 & 0.333 \\
\hline $\mathrm{C}_{2}$ & 0.167 & 1.000 & 0.500 & 0.667 & 0.667 & 0.000 \\
\hline $\mathrm{C}_{3}$ & 0.400 & 0.400 & 1.000 & 0.600 & 0.200 & 0.000 \\
\hline$D_{1}$ & 0.000 & 0.833 & 0.417 & 0.917 & 1.000 & 0.833 \\
\hline $\mathrm{D}_{2}$ & 0.778 & 0.250 & 0.000 & 1.000 & 0.278 & 0.639 \\
\hline $\mathrm{D}_{3}$ & 1.000 & 0.000 & 0.529 & 0.706 & 0.412 & 0.353 \\
\hline $\mathrm{D}_{4}$ & 0.667 & 0.364 & 1.000 & 0.303 & 0.424 & 0.000 \\
\hline
\end{tabular}

4.2. Index Optimization. The system indicators are classified into input-type and output-type. According to the ISM model, an element relationship table is first constructed according to the influence relationship between the indicators; an adjacency matrix $A_{1}$ can be established according to the element relationship table. Matrix operations are performed on the adjacency matrix $A_{1}$ to find the reachable matrix $M_{1}$ (Figure 5).

The reachability matrix is decomposed to find the intersection $R\left(S_{i}\right) \cap Q\left(S_{i}\right)$ of the reachability set $R\left(S_{i}\right)$ and the antecedent set, $Q\left(S_{i}\right)$. The reachability matrix is then decomposed according to the $R\left(S_{i}\right) \cap Q\left(S_{i}\right)=R\left(S_{i}\right)$ condition, and the qualified index elements $S_{i}$ are extracted and defined as the top-level index. Next, the remaining index elements are re-decomposed: the top-level index is removed, and the qualified index elements are extracted and defined as second-level indicators. The same is true until all indicators are extracted. A schematic diagram of the relationship between the index elements can be constructed according to the extraction process and results (Figure 6).

According to the schematic diagram of the relationship between indicator elements, 16 indicators are distributed at both ends of the hierarchy. According to the different driving effects, there are two key indicator categories: input and output indicators. According to the improved D-DEA algorithm, control variable analysis was performed on 16 indicators; calculation results are shown in Table 4 (gray bottom indicators are input indicators; others are output indicators).

The average efficiency change value of the three inputtype indicators and the overall deviation rate of the three output-type indicators are the smallest (Table 4 ). The impact of these six indicators on the subsequent evaluation is very small. The index is screened, and the optimized index system is shown in Table 5.

\subsection{Utility Evaluation}

4.3.1. Calculation of Indicator Weight. For the calculation of the index weights, a comprehensive weighting method is used and combined with the design of the weighting model. Tables 6 and 7 show the specific weight comparisons and final results.

4.3.2. Comprehensive Utility Evaluation. Based on the conversion coefficient setting differences, the overall utility of the project is evaluated and ranked from risk preference and risk avoidance perspectives. The risk preference conversion and risk avoidance conversion coefficients were set to 0.8 and 0.4 , respectively.

(1) Risk Appetite. For risk appraisers, the conversion factor and parameters $\alpha$ and $\beta$ are set to 0.8 and 0.5 , respectively. The dimensionless values of each indicator are substituted into the utility function to obtain the utility value of the corresponding indicator for each item (Table 8).

The distance vector merging rule is used to obtain the utility values of various project category layers (Figure 7). The utility advantages of each project differ in different dimensions. For example, in the economic benefit dimension, the evaluation values of projects $\mathrm{B}$ and $\mathrm{D}$ are greater than 0.8 , better than those of the other projects. Thus, these projects have superior economic utility. In the social benefit dimension, only projects $\mathrm{E}$ and $\mathrm{F}$ had evaluation values greater than 0.8 , whereas other projects had unsatisfactory evaluation results. Only projects $\mathrm{A}$ and $\mathrm{F}$ have environmental benefit evaluation results greater than 0.8 , whereas other projects are expected to have poor results. The evaluation results of the technical benefits of each project are approximately 0.7 .

Similarly, the distance vector merging rule is used to obtain the comprehensive utility value of various projects (Figure 8). The comprehensive utility evaluation results are ranked in the following order: Project $\mathrm{B}>$ Project $\mathrm{F}>$ Project A > Project D> Project E $>$ Project C.

(2) Risk Aversion. For risk-avoidance evaluators, the conversion factor and the parameters $\alpha$ and $\beta$ are set to 0.4 and 0.5 , respectively. The non-dimensionalized values of each 


\begin{tabular}{|c|c|c|c|c|c|c|c|c|c|c|c|c|c|c|c|c|}
\hline & $\mathrm{A}_{1}$ & $\mathrm{~A}_{2}$ & $\mathrm{~A}_{3}$ & $\mathrm{~A}_{4}$ & $\mathrm{~A}_{5}$ & $\mathrm{~A}_{6}$ & $\mathrm{~B}_{1}$ & $\mathrm{~B}_{2}$ & $\mathrm{~B}_{3}$ & $\mathrm{C}_{1}$ & $\mathrm{C}_{2}$ & $\mathrm{C}_{3}$ & $\mathrm{D}_{1}$ & $\mathrm{D}_{2}$ & $\mathrm{D}_{3}$ & $\mathrm{D}_{4}$ \\
\hline $\mathrm{A}_{1}$ & 1 & 1 & 1 & 0 & 0 & 0 & 1 & 0 & 0 & 0 & 1 & 0 & 0 & 0 & 0 & 1 \\
\hline $\mathrm{A}_{2}$ & 1 & 1 & 1 & 1 & 1 & 1 & 0 & 0 & 0 & 0 & 0 & 0 & 0 & 0 & 0 & 1 \\
\hline $\mathrm{A}_{3}$ & 0 & 0 & 1 & 1 & 0 & 0 & 0 & 0 & 0 & 0 & 0 & 0 & 0 & 0 & 0 & 0 \\
\hline $\mathrm{A}_{4}$ & 0 & 0 & 0 & 1 & 0 & 0 & 0 & 0 & 0 & 0 & 0 & 0 & 0 & 0 & 0 & 0 \\
\hline $\mathrm{A}_{5}$ & 0 & 0 & 0 & 0 & 1 & 1 & 0 & 0 & 0 & 0 & 0 & 0 & 0 & 0 & 0 & 0 \\
\hline $\mathrm{A}_{6}$ & 0 & 0 & 0 & 0 & 0 & 1 & 1 & 1 & 0 & 0 & 0 & 0 & 0 & 0 & 0 & 0 \\
\hline $\mathrm{B}_{1}$ & 0 & 0 & 0 & 0 & 0 & 0 & 1 & 0 & 0 & 1 & 1 & 1 & 1 & 1 & 0 & 1 \\
\hline $\mathrm{B}_{2}$ & 0 & 1 & 1 & 1 & 0 & 0 & 1 & 1 & 1 & 0 & 0 & 0 & 0 & 0 & 0 & 1 \\
\hline $\mathrm{B}_{3}$ & 0 & 1 & 1 & 1 & 0 & 0 & 1 & 1 & 1 & 0 & 0 & 0 & 0 & 0 & 0 & 1 \\
\hline $\mathrm{C}_{1}$ & 0 & 0 & 0 & 0 & 0 & 0 & 0 & 0 & 0 & 1 & 1 & 1 & 0 & 0 & 0 & 0 \\
\hline $\mathrm{C}_{2}$ & 0 & 0 & 0 & 0 & 0 & 0 & 0 & 0 & 0 & 1 & 1 & 1 & 0 & 0 & 0 & 0 \\
\hline $\mathrm{C}_{3}$ & 0 & 0 & 0 & 0 & 0 & 0 & 0 & 0 & 0 & 1 & 1 & 1 & 0 & 0 & 0 & 0 \\
\hline $\mathrm{D}_{1}$ & 0 & 0 & 0 & 0 & 1 & 0 & 0 & 0 & 0 & 0 & 0 & 0 & 1 & 0 & 1 & 1 \\
\hline $\mathrm{D}_{2}$ & 0 & 0 & 0 & 0 & 1 & 0 & 0 & 0 & 0 & 0 & 0 & 0 & 1 & 1 & 0 & 0 \\
\hline $\mathrm{D}_{3}$ & 1 & 0 & 0 & 0 & 1 & 0 & 0 & 0 & 0 & 0 & 0 & 0 & 0 & 1 & 1 & 0 \\
\hline $\mathrm{D}_{4}$ & 0 & 1 & 0 & 0 & 1 & 0 & 0 & 0 & 0 & 0 & 0 & 0 & 0 & 0 & 1 & 1 \\
\hline
\end{tabular}

Figure 5: Reachable matrix.

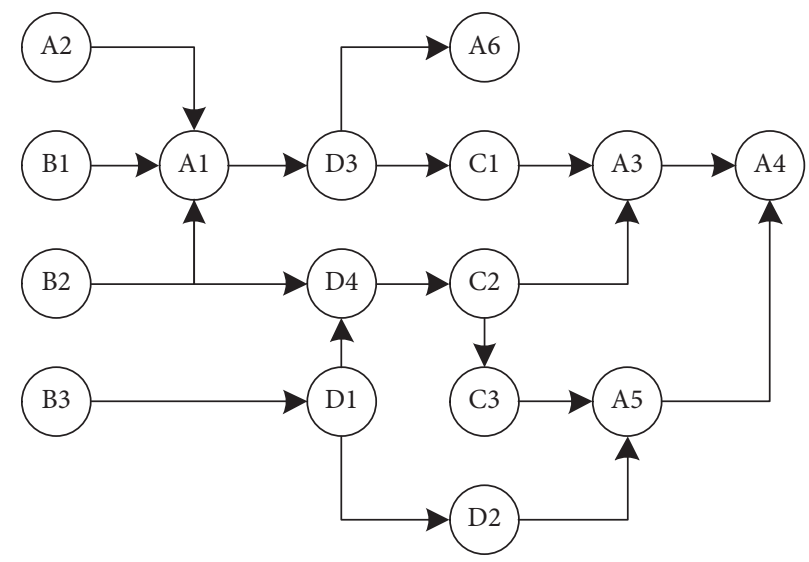

FIGURE 6: Indicator relationship diagram.

TABLE 4: Evaluation results of the improved D-DEA algorithm.

\begin{tabular}{|c|c|c|c|c|c|c|c|c|}
\hline Index/project & A & $\mathrm{B}$ & $\mathrm{C}$ & $\mathrm{D}$ & $\mathrm{E}$ & $\mathrm{F}$ & Average efficiency change (\%) & Overall deviation rate (\%) \\
\hline $\mathrm{A}_{1}$ & 0.917 & 1 & 0.944 & 1 & 0.911 & 0.964 & 3.90 & 8.73 \\
\hline$A_{2}$ & 1 & 0.937 & 0.92 & 0.927 & 0.93 & 0.963 & 2.49 & 6.77 \\
\hline$A_{3}$ & 1 & 0.94 & 0.974 & 0.955 & 0.976 & 0.905 & 4.88 & 7.41 \\
\hline $\mathrm{A}_{4}$ & 1 & 1 & 0.972 & 0.936 & 0.976 & 1 & 4.65 & 5.67 \\
\hline $\mathrm{A}_{5}$ & 0.935 & 0.97 & 1 & 0.934 & 0.943 & 0.91 & 6.64 & 7.08 \\
\hline $\mathrm{A}_{6}$ & 0.967 & 0.923 & 0.956 & 1 & 0.961 & 0.959 & 3.19 & 5.50 \\
\hline $\mathrm{B}_{1}$ & 1 & 0.942 & 0.948 & 0.907 & 0.914 & 0.953 & 3.30 & 7.42 \\
\hline $\mathrm{B}_{2}$ & 0.908 & 0.942 & 0.932 & 1 & 0.961 & 0.903 & 4.68 & 8.06 \\
\hline $\mathrm{B}_{3}$ & 1 & 1 & 0.921 & 0.946 & 0.931 & 1 & 2.72 & 8.44 \\
\hline $\mathrm{C}_{1}$ & 1 & 0.935 & 0.906 & 0.965 & 0.953 & 0.943 & 2.35 & 7.03 \\
\hline $\mathrm{C}_{2}$ & 0.93 & 0.908 & 0.92 & 0.904 & 1 & 0.934 & 6.14 & 7.83 \\
\hline $\mathrm{C}_{3}$ & 0.95 & 0.95 & 0.972 & 0.965 & 1 & 0.953 & 5.32 & 4.32 \\
\hline $\mathrm{D}_{1}$ & 1 & 0.929 & 0.923 & 0.945 & 1 & 0.992 & 3.01 & 8.15 \\
\hline $\mathrm{D}_{2}$ & 0.957 & 1 & 0.927 & 0.968 & 0.939 & 0.914 & 4.76 & 6.94 \\
\hline $\mathrm{D}_{3}$ & 1 & 0.952 & 0.913 & 1 & 0.929 & 0.902 & 2.41 & 9.55 \\
\hline $\mathrm{D}_{4}$ & 0.953 & 1 & 0.927 & 0.924 & 0.904 & 0.928 & 4.98 & 7.50 \\
\hline Original value & 1 & 0.932 & 0.907 & 1 & 0.912 & 1 & - & - \\
\hline
\end{tabular}


Table 5: Index system optimization results.

\begin{tabular}{|c|c|c|c|c|c|c|c|}
\hline Second layer & Third layer & A & $\mathrm{B}$ & $\mathrm{C}$ & $\mathrm{D}$ & E & $\mathrm{F}$ \\
\hline \multirow{3}{*}{ Economic benefits } & New investment included in fixed assets ratio & 0.500 & 0.000 & 1.000 & 0.773 & 0.636 & 0.409 \\
\hline & Asset utilization efficiency & 0.700 & 0.000 & 0.800 & 0.400 & 1.000 & 0.400 \\
\hline & Unit asset pricing depreciation fee & 0.600 & 1.000 & 0.400 & 0.200 & 0.000 & 0.800 \\
\hline \multirow{2}{*}{ Social benefit } & Investment power growth ratio & 1.000 & 0.143 & 0.000 & 0.571 & 0.429 & 0.071 \\
\hline & User reliability & 0.000 & 0.750 & 1.000 & 0.875 & 0.500 & 0.125 \\
\hline \multirow{2}{*}{ Environmental benefits } & $\mathrm{CO}_{2}$ emission reduction rate & 0.000 & 0.222 & 0.667 & 1.000 & 0.444 & 0.333 \\
\hline & Proportion of clean energy power generation capacity & 0.167 & 1.000 & 0.500 & 0.667 & 0.667 & 0.000 \\
\hline \multirow{3}{*}{ Technical benefits } & Qualified rate of voltage & 0.000 & 0.833 & 0.417 & 0.917 & 1.000 & 0.833 \\
\hline & Node voltage ratio & 0.778 & 0.250 & 0.000 & 1.000 & 0.278 & 0.639 \\
\hline & Network coordination & 0.667 & 0.364 & 1.000 & 0.303 & 0.424 & 0.000 \\
\hline
\end{tabular}

TABLE 6: Comparison result of three-level index weights.

\begin{tabular}{lccccc}
\hline & Only reference comparison method & AHP & Coefficient of variation method & Entropy weight method & Comprehensive weight \\
\hline$A_{1}$ & 0.412 & 0.512 & 0.287 & 0.254 & 0.321 \\
$A_{3}$ & 0.425 & 0.321 & 0.612 & 0.595 & 0.538 \\
$A_{5}$ & 0.163 & 0.167 & 0.101 & 0.151 & 0.141 \\
$B_{1}$ & 0.652 & 0.576 & 0.333 & 0.376 & 0.451 \\
$B_{2}$ & 0.348 & 0.424 & 0.667 & 0.624 & 0.549 \\
$C_{1}$ & 0.432 & 0.641 & 0.772 & 0.339 & 0.672 \\
$C_{2}$ & 0.568 & 0.359 & 0.228 & 0.332 & 0.328 \\
$D_{1}$ & 0.428 & 0.418 & 0.287 & 0.279 & 0.336 \\
$D_{2}$ & 0.331 & 0.411 & 0.256 & 0.389 & 0.298 \\
$D_{4}$ & 0.241 & 0.171 & 0.457 & 0.366 \\
\hline
\end{tabular}

TABLE 7: Indicator weight results.

\begin{tabular}{|c|c|c|c|c|}
\hline Secondary & $\begin{array}{c}\text { Weight of this } \\
\text { layer }\end{array}$ & Third & $\begin{array}{l}\text { Weight of this } \\
\text { layer }\end{array}$ & $\begin{array}{c}\text { Comprehensive } \\
\text { weight }\end{array}$ \\
\hline \multirow{3}{*}{ Economic benefits } & \multirow{3}{*}{0.46} & New investment included in fixed assets ratio & 0.321 & 0.148 \\
\hline & & Asset utilization efficiency & 0.538 & 0.247 \\
\hline & & Unit asset pricing depreciation fee & 0.141 & 0.065 \\
\hline \multirow{2}{*}{ Social benefit } & \multirow{2}{*}{0.201} & Investment power growth ratio & 0.451 & 0.091 \\
\hline & & User reliability & 0.549 & 0.110 \\
\hline \multirow{2}{*}{$\begin{array}{l}\text { Environmental } \\
\text { benefits }\end{array}$} & \multirow[b]{2}{*}{0.201} & \multirow{2}{*}{$\begin{array}{c}\mathrm{CO}_{2} \text { emission reduction rate } \\
\text { Proportion of clean energy power generation } \\
\text { capacity }\end{array}$} & 0.672 & 0.135 \\
\hline & & & 0.328 & 0.066 \\
\hline \multirow{3}{*}{ Technical benefits } & \multirow{3}{*}{0.139} & Qualified rate of voltage & 0.336 & 0.047 \\
\hline & & Node voltage ratio & 0.298 & 0.041 \\
\hline & & Network coordination & 0.366 & 0.051 \\
\hline
\end{tabular}

TABLE 8: Utility value of the corresponding indicator of the investment project.

\begin{tabular}{|c|c|c|c|c|c|c|}
\hline Index \project & Project A & Project B & Project C & Project D & Project E & Project $\mathrm{F}$ \\
\hline $\mathrm{A}_{1}$ & 0.548 & 0.735 & 0.245 & 0.405 & 0.481 & 0.587 \\
\hline $\mathrm{A}_{3}$ & 0.447 & 0.735 & 0.388 & 0.591 & 0.245 & 0.591 \\
\hline $\mathrm{A}_{5}$ & 0.500 & 0.245 & 0.591 & 0.668 & 0.735 & 0.388 \\
\hline $\mathrm{B}_{1}$ & 0.245 & 0.688 & 0.735 & 0.514 & 0.579 & 0.712 \\
\hline $\mathrm{B}_{2}$ & 0.735 & 0.419 & 0.245 & 0.339 & 0.548 & 0.694 \\
\hline $\mathrm{C}_{1}$ & 0.735 & 0.660 & 0.466 & 0.245 & 0.572 & 0.618 \\
\hline $\mathrm{C}_{2}$ & 0.680 & 0.245 & 0.548 & 0.466 & 0.466 & 0.735 \\
\hline $\mathrm{D}_{1}$ & 0.735 & 0.367 & 0.584 & 0.310 & 0.245 & 0.367 \\
\hline $\mathrm{D}_{2}$ & 0.402 & 0.650 & 0.735 & 0.245 & 0.640 & 0.480 \\
\hline $\mathrm{D}_{4}$ & 0.466 & 0.606 & 0.245 & 0.630 & 0.581 & 0.735 \\
\hline
\end{tabular}




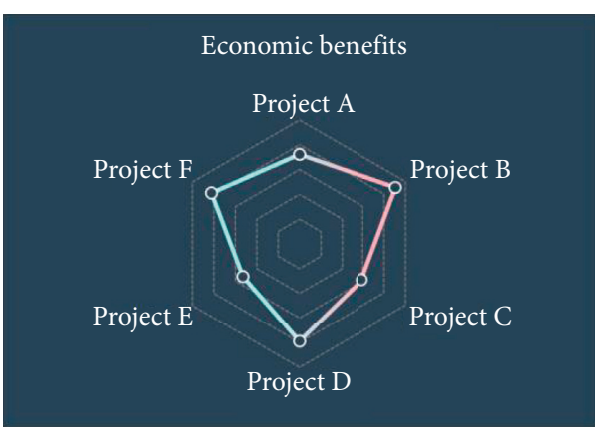

(a)

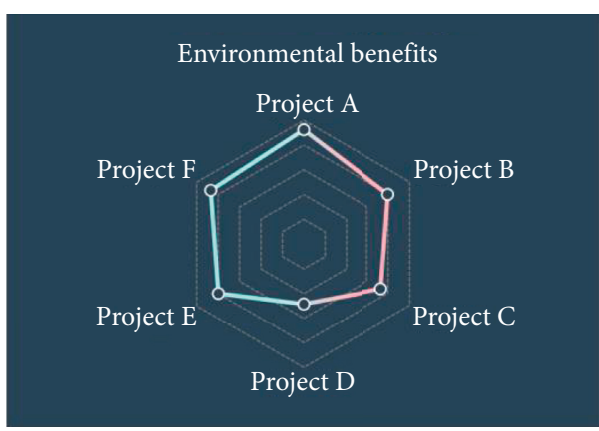

(c)

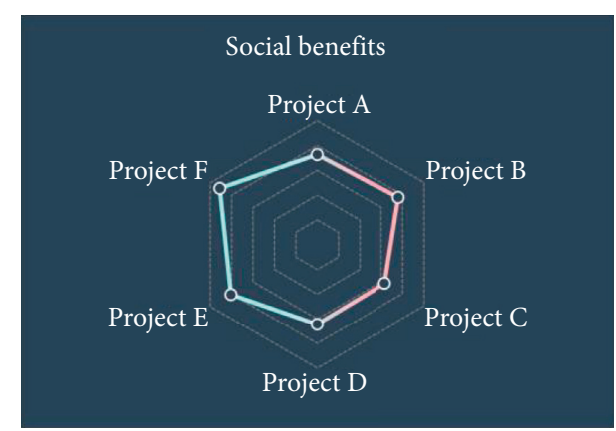

(b)

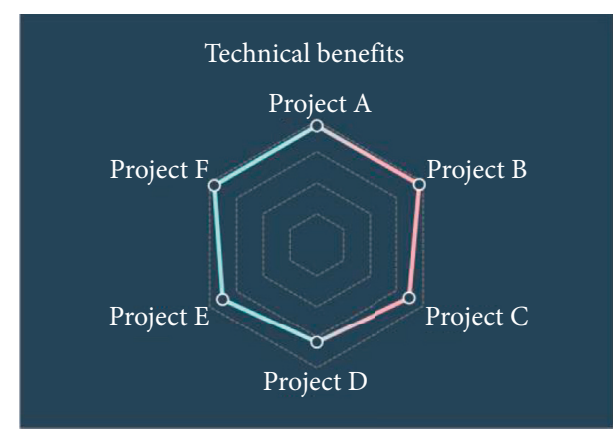

(d)

FIGURE 7: Results of project utility evaluation in each dimension.

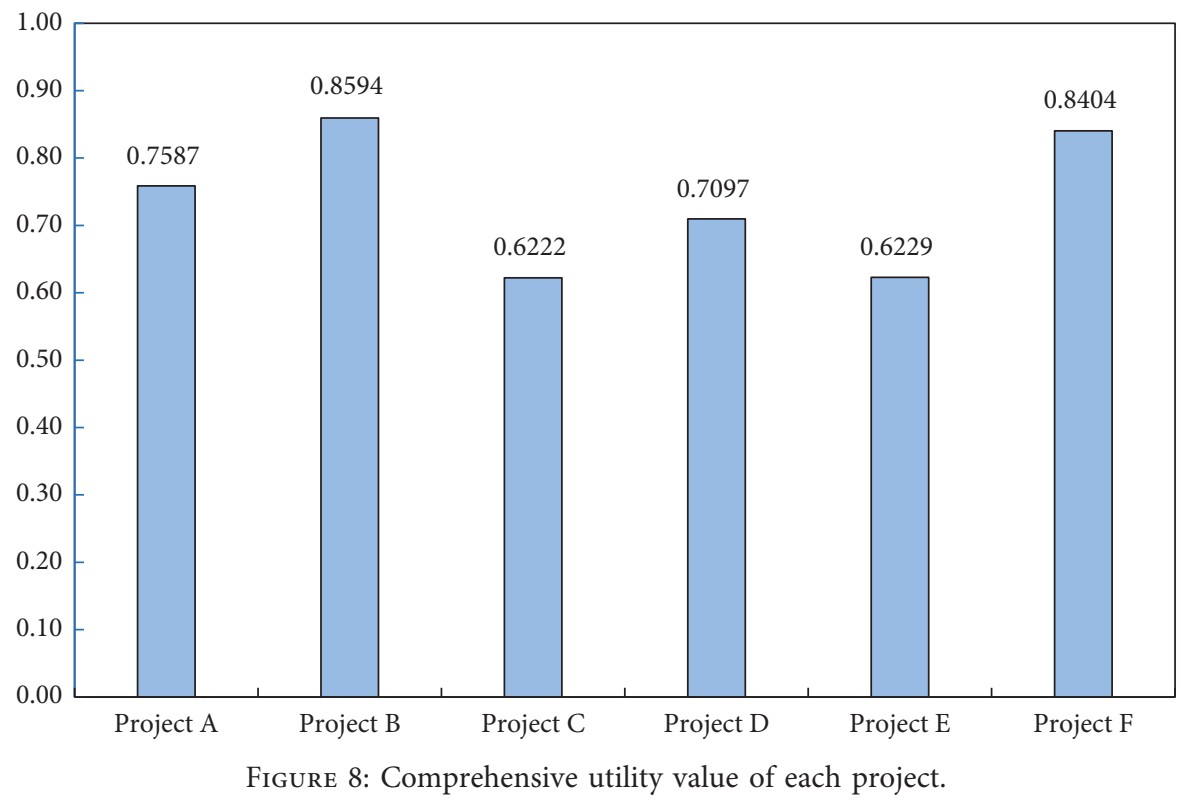

indicator are substituted into the utility function to obtain the utility value of the corresponding indicator for each project (Table 9).

The distance vector merging rule is used to obtain the utility value of various project category layers (Figure 9). The utility advantages of each project differ in different dimensions. For example, in the economic benefit dimension, the evaluation value of projects $C$ and $E$ is greater than 0.9 , which is significantly better than that of the other projects. Thus, these projects have superior economic utility. In the social benefit dimension, only project $\mathrm{D}$ had an evaluation value greater than 0.9 , whereas other projects had unsatisfactory evaluation results. Only project D had environmental benefit evaluation results greater than 0.8 , whereas other projects are expected to have poor results. The evaluation results of the technical benefits of each project are approximately 0.85 .

The distance vector merging rule is used to obtain the comprehensive utility value of various projects (Figure 10). The results of the comprehensive utility evaluation are 
TABLE 9: Utility value of the corresponding indicator of the investment project.

\begin{tabular}{|c|c|c|c|c|c|c|}
\hline Index \project & Project A & Project B & Project C & Project D & Project E & Project $\mathrm{F}$ \\
\hline $\mathrm{A}_{1}$ & 0.631 & 0.388 & 0.794 & 0.726 & 0.681 & 0.595 \\
\hline $\mathrm{A}_{3}$ & 0.703 & 0.388 & 0.735 & 0.591 & 0.794 & 0.591 \\
\hline $\mathrm{A}_{5}$ & 0.668 & 0.794 & 0.591 & 0.500 & 0.388 & 0.735 \\
\hline $\mathrm{B}_{1}$ & 0.794 & 0.471 & 0.388 & 0.658 & 0.603 & 0.431 \\
\hline $\mathrm{B}_{2}$ & 0.388 & 0.719 & 0.794 & 0.758 & 0.631 & 0.461 \\
\hline $\mathrm{C}_{1}$ & 0.388 & 0.511 & 0.691 & 0.794 & 0.609 & 0.563 \\
\hline $\mathrm{C}_{2}$ & 0.483 & 0.794 & 0.631 & 0.691 & 0.691 & 0.388 \\
\hline $\mathrm{D}_{1}$ & 0.388 & 0.745 & 0.598 & 0.770 & 0.794 & 0.745 \\
\hline $\mathrm{D}_{2}$ & 0.728 & 0.524 & 0.388 & 0.794 & 0.537 & 0.682 \\
\hline $\mathrm{D}_{4}$ & 0.691 & 0.576 & 0.794 & 0.549 & 0.601 & 0.388 \\
\hline
\end{tabular}

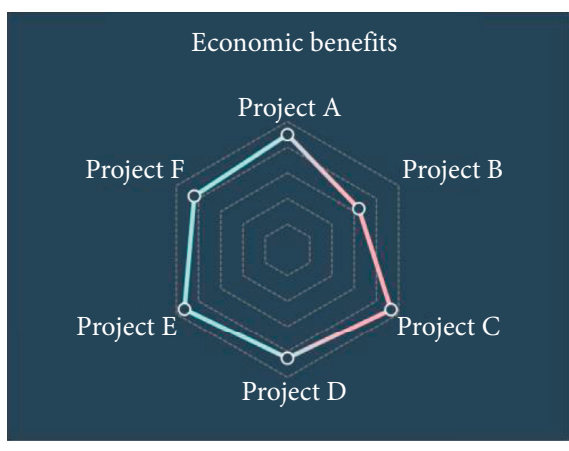

(a)

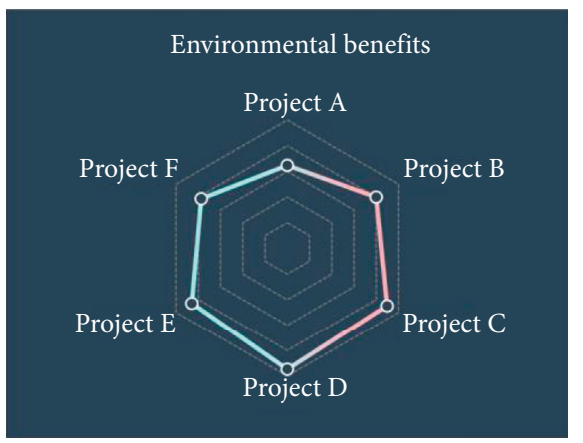

(c)

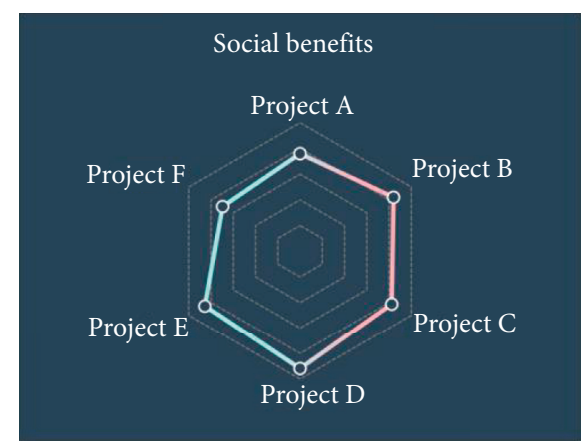

(b)

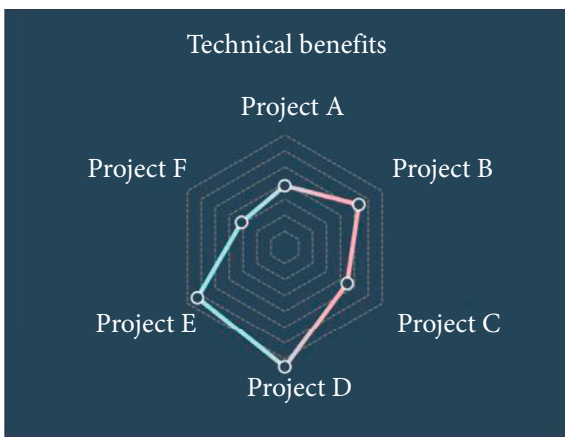

(d)

FIGURE 9: Results of project utility evaluation in each dimension.

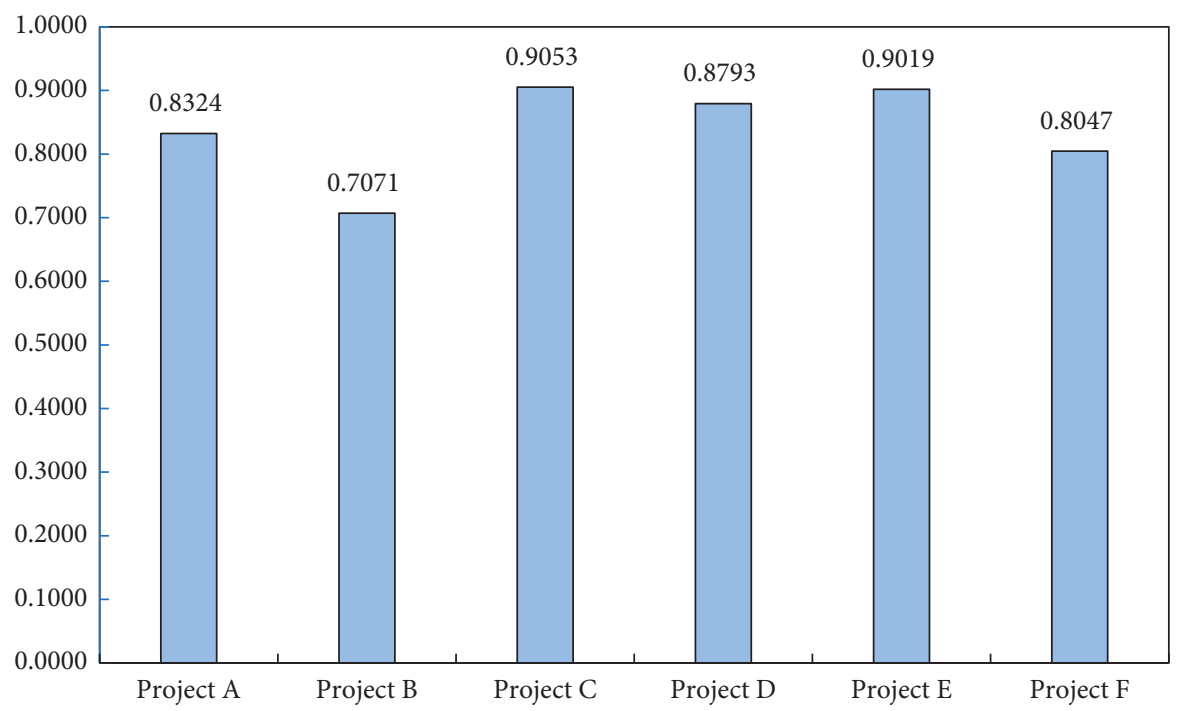

FIGURE 10: Comprehensive utility value of each project. 
ranked in the following order: Project $\mathrm{C}>$ Project $\mathrm{E}>$ Project $\mathrm{D}>$ Project $\mathrm{A}>$ Project $\mathrm{F}>$ Project $\mathrm{B}$.

The resulting rankings of the comprehensive utility evaluation of risk appetite and risk avoidance are opposite, partially verifying that the constructed utility evaluation model can provide different evaluation results for different risk appraisers. Therefore, the risk appetite of the decisionmaker can be considered when making a decision, and the decision-maker can be guided towards a rational decision.

\section{Conclusion}

This study optimized the evaluation system and resolved deficiencies with the previous power grid investment evaluation index by constructing the grid investment effectiveness evaluation index system and the utility evaluation model based on risk preference. Index redundancy is high but changes the past grid investment evaluation results of a single problem. Taking a regional power grid IEEE-RTS79 system as an example, the data results of six power grid investment projects are selected for analysis, and the validity of the constructed model is verified. The conclusions of this study are as follows:

(1) When constructing the grid investment effectiveness evaluation index system, there is a high correlation between certain indicators that makes the evaluation results unreadable. ISM-DEA modeling reduces this risk and improves the evaluation effectiveness.

(2) Compared with the results of traditional indicator weights, the multi-objective comprehensive weighting method proposed in this study not only considers the characteristics of subjective and objective weights but also considers the limitations of various methods, with minimum deviation and the optimal trend as the optimization goals. The specified index weights better agree with the requirements of evaluation rationality.

(3) The example results show that the utility function model of the risk preferences of the decision-makers is adopted by adjusting the risk preference coefficient; two more extreme coefficients are set in this study to achieve two different evaluation results, indicating that the evaluation result of the effectiveness of power grid investment is not fixed but rather affected by future risk prediction.

The effectiveness of grid investment is not limited to the research scope of this article but is affected by factors such as future changes in transmission, distribution price policies, and fluctuations in power market supply and demand. More in-depth exploration of the effectiveness of grid investment is the key to improve the scientific rationality of grid investment and to guide future grid investment work. Additionally, the popularity of electric vehicle charging piles will lead to distributed power access and will become an important factor affecting the optimization of grid investment. The evaluation effectiveness of the grid investment constructed in this study is also a very important research direction in the future for analyzing the charge and discharge uncertainty of electric vehicles.

\section{Data Availability}

The initial data of the dissertation mainly come from the project research. Some data have confidentiality agreements. Except for the data mentioned in the dissertation that can be disclosed, other data cannot be disclosed due to confidentiality issues.

\section{Conflicts of Interest}

The authors declare that they have no conflicts of interest.

\section{Acknowledgments}

This paper was supported by China Southern Power Grid Technology Project (Grant no. ZBKJXM20180369).

\section{References}

[1] State Council of the CPC Central Committee: Several opinions on further deepening the reform of the power system. 2015.

[2] National Development and Reform Commission: Provincial Grid Transmission and Distribution Pricing Measures Development and Reform Prices. 2020.

[3] G. N. Psarros and S. A. Papathanassiou, "Evaluation of battery-renewable hybrid stations in small-isolated systems," IET Renewable Power Generation, vol. 14, no. 1, pp. 39-51, 2020.

[4] W. Ma, J. Fan, S. Fang, and G. Liu, "Techno-economic potential evaluation of small-scale grid-onnected renewable power systems in China," Energy Conversion and Management, vol. 196, pp. 430-442, 2019.

[5] X. Yu and Z. Tan, "Research on the differential evaluation of smart grid in the improved hall 3D perspective," Modern Electric Power, vol. 32, no. 4, pp. 42-48, 2015.

[6] X. Yu, W. Zhang, and Z. Tan, "Evaluation of technical efficiency of distribution network considering environmental differences," Electric Power Construction, vol. 37, no. 7, pp. 112-118, 2016.

[7] Q. Jiang, R. Huang, Y. Huang, S. Chen et al., "Application of $\mathrm{BP}$ neural network based on genetic algorithm optimization in evaluation of power grid investment risk," IEEE Access, vol. 7, pp. 154827-154835, 2019.

[8] X. Han, H. Zhang, and X. Yu, L. Wang, "Economic evaluation of grid-connected micro-grid system with photovoltaic and energy storage under different investment and financing models," Applied Energy, vol. 184, pp. 103-118, 2016.

[9] W. Guo and H. Jin, "Research on evaluation of investment benefits of power grid based on decision model analysis," Automation and Instrumentation, vol. 5, pp. 175-178, 2019.

[10] X. Yu, Z. Tan, and G. Qu, "Research on differentiated electricity price package based on electricity customer evaluation," China Electric Power, vol. 53, no. 2, pp. 9-19, 2020.

[11] X. Yu, Research on Optimization Model of Electricity Purchase and Sale Transactions of Electricity Sale Companies under the Electricity Market Environment, North China of Electric Power University, Beijing, China, 2018.

[12] D. Xing, Research on Grid Investment Evaluation Based on Set Pair Analysis Method under New Power Reform, North China Electric Power University, Beijing, China, 2019. 
[13] Y. He, W. Liu, J. Jiao, and J. Guan, "Evaluation method of benefits and efficiency of grid investment in China: a case study," Engineering Economist, vol. 63, no. 1, pp. 66-86, 2018.

[14] Y. Sun, X. Yu, Z. Tan, X. Xu, and Q. Yan, "Efficiency evaluation of operation analysis systems based on dynamic data envelope analysis models from a big data perspective," Applied Sciences, vol. 7, no. 6, p. 624, 2017.

[15] X. Yu and Y. Sun, "Trading risk control model of electricity retailers in multi-level power market of China," Energy Science \& Engineering, vol. 7, no. 6, pp. 2756-2767, 2019.

[16] X. Yu and Y. Geng, "Complementary configuration research of new combined cooling, heating, and power system driven by renewable energy under energy management modes," Energy Technology, vol. 7, no. 10, Article ID 1900409, 2019.

[17] M. Negnevitsky, D. H. Nguyen, and M. Piekutowski, "Risk assessment for power system operation planning with high wind power penetration," IEEE Transactions on Power Systems, vol. 30, no. 3, pp. 1359-1368, 2015.

[18] Z. Liang, H. Chen, X. Wang, S. Chen, and C. Zhang, "Risk-based uncertainty set optimization method for energy management of hybrid AC/DC microgrids with uncertain renewable generation," IEEE Transactions on Smart Grid, vol. 11, no. 2, pp. 1526-1542, 2020.

[19] R. Karki, S. Thapa, and R. B. Billinton, "A simplified riskbased method for short-term wind power commitment," IEEE Transactions on Sustainable Energy, vol. 3, no. 3, pp. 498-505, 2012.

[20] G. Cao, W. Gu, P. Li et al., "Operational risk evaluation of active distribution networks considering cyber contingencies," IEEE Transactions on Industrial Informatics, vol. 16, no. 6, pp. 3849-3861, 2020.

[21] Ma Qian, Z. Wang, X. Pan et al., "Evaluation method of grid investment decision-making based on utility function in the environment of new power reform," Electric Power Automation Equipment, vol. 39, no. 12, pp. 198-204, 2019.

[22] Y. He, Research on Multi-User Assisted Wind Power Consumption Optimization Model Based on Demand Response, North China Electric Power University, Beijing, China, 2016. 